\title{
Fetal Alcohol Syndrome: Failure of Zinc Supplementation to Reverse the Effect of Ethanol on Placental Transport of Zinc
}

\author{
FAYEZ $\mathrm{K}$. GHISHAN ${ }^{(22)}$ AND HARRY L. GREENE \\ Vanderbilt University Medical Center, Department of Pediatric Gastroenterology-Nutrition, Nashville, Tennessee, \\ $U S A$
}

\begin{abstract}
Summary
Clinical observation and experimental animal models indicate that chronic ethanol ingestion during pregnancy results in a well recognized state in the fetus termed fetal alcohol syndrome. We have recently demonstrated, using an in vivo technique, that placental transport of zinc, an essential element for protein synthesis, is significantly decreased by short-term and long-term ethanol ingestion during pregnancy; moreover, total fetal zinc concentration in the offspring of mothers on chronic ethanol diet was significantly decreased compared to pair-fed controls. These findings indicated that the growth retardation in fetal alcohol syndrome may be due partly to a decrease in the transfer of zinc to the fetus. Our current study was designed to investigate whether the defect in placental transport can be overcome by supplementation of the ethanol diet with either 10 or $40 \mathrm{mg}$ of zinc per liter in isocalorically pair-fed pregnant rats. The results indicate that supplementation of the ethanol diet with zinc did not overcome the defect in placental transport of zinc.
\end{abstract}

Ethyl alcohol is the most widely abused drug in North America (15). Historically, alcohol ingestion during pregnancy has often been noted to have an adverse effect on offspring. More recent clinical observations $(8,13,14,17)$ and experimental animal models $(1,19,19)$ have indicated that maternal ethanol ingestion during pregnancy results in a well recognized state in the fetus termed fetal alcohol syndrome $(13,14)$. Classically these infants are growth retarded and show no evidence of catch-up growth $(8$, $13,14,17)$.

Because zinc is an essential trace element required for protein synthesis and subsequent growth (3) and because prenatal zinc deficiency can cause fetal growth retardation and congenital malformations (11), we postulated that ethanol may inhibit the placental transport of zinc to the fetus. Recently, we have demonstrated that chronic ethanol ingestion in the rat resulted in fetal growth retardation; moreover, placental zinc transport and fetal uptake of zinc was decreased 40 and $30 \%$, respectively in rats administered ethanol chronically compared to pair-fed controls (5). Furthermore, zinc concentration in the fetus was significantly decreased in the offspring of rats administered ethanol chronically when compared to pair-fed controls. We postulated, therefore, that inhibition of placental transport of zinc by ethanol may be a factor in the growth retardation seen in fetal alcohol syndrome.

The current study was designed to answer the question whether the defect in placental zinc transport can be overcome by supplementation with either physiologic or pharmacologic doses of zinc added to the ethanol diet.

\section{MATERIALS AND METHODS}

Animals. Pregnant Sprague-Dawley rats were obtained from Harlan Laboratories (Indianapolis, IN) in the second day of pregnancy (first day of gestation calculated from the first vaginal sperm positive day). The rats were pair-fed a Lieber-DeCarli liquid diet (Bioserv, Inc., Frenchtown, NJ) containing either 5\% ethanol (experimental group) or isocalorically balanced maltosedextrins (pair-fed control group). The experimental group was divided into three groups. The first group was fed the ethanol diet, which contained $5 \mathrm{mg} /$ liter of zinc. The second group was fed the ethanol diet plus supplemental $10 \mathrm{mg}$ of zinc per liter and the third group was fed the ethanol diet plus supplemental $40 \mathrm{mg}$ of zinc. Each group consisted of eight rats. The three experimental groups and the control group were all pair-fed on a day-to-day basis. The pair feeding was carried out on the basis of rat: rat pairing. The composition of the diets is shown on Table 1. Each $1 \mathrm{ml}$ of diet contained $1 \mathrm{kcal}$. Rats ingested an average of $70 \mathrm{ml} /$ day. Zinc concentration in the diet was measured in each batch by atomic absorption spectrophotometry.

In vivo zinc transport studies. On gestation day 20 , pregnant rats were anesthetized with chloral hydrate $300 \mathrm{mg} / \mathrm{kg}$ body weight. Rats were placed on a heating pad and their temperature was kept at $30-37^{\circ} \mathrm{C}$ by continuous monitoring with a rectal probe. $\left[{ }^{65} \mathrm{Zn}\right]$, $2 \mu \mathrm{Ci} / 100 \mathrm{~g}$ body weight, was injected [specific activity, $10 \mathrm{mCi}$ / mg zinc chloride] (Amersham Inc., Arlington Heights, IL) into an exposed femoral vein. Ten minutes later, the two uterine arteries and two ovarian arteries were ligated and the uterus was excised. Blood was collected from the maternal aorta. The uterus was then opened, the amniotic sac was incised to deliver the fetus and placenta. Wet weight of the tissues was determined immediately, then stored in appropriate tubes for counting of $\left[{ }^{65} \mathrm{Zn}\right]$ radioactivity in a gamma counter (Packard Model 3001). Results were expressed as \% injected dose per $\mathrm{g}$ fetus and placenta. Counting efficiency of $\left[{ }^{65} \mathrm{Zn}\right]$ in tissue was approximately $75-80 \%$. Tissue concentration of zinc was determined in serum and placenta, femur and fetal tissues by atomic absorption spectrophotometer (Perkin-Elmer Model 6003) after dry ashing. NBS bovine liver (certified reference material \#1577) was used as a standard reference for dry ashing. Serum samples for zinc analysis were collected in a special plastic syringe without rubber plunger (Serum Monovette, Sarstedt, Germany) to avoid contamination. Tissue samples were kept in crucibles washed twice with $0.1 \mathrm{~N} \mathrm{HCl}$ and double distilled water. Maternal blood ethanol concentration was measured by alcohol dehydrogenase method modified from Calbiochem Ethanol Stat Packs (Calbiochem-Behring Corp., San Diego, CA) in $10 \mu \mathrm{l}$ aliquots of blood samples.

Statistical analysis. The paired Student's $t$ test was used for statistical comparisons between two means. Multiple mean comparison of paired data to the control group were made using oneway analysis of variance, then Dunnett's procedure. The level of significance was chosen as $(P<0.05)(12)$.

\section{RESULTS}

Table 2 depicts initial and final maternal body weight in the groups of rats studied. There were no significant differences 570 
Table 1. Composition ( $\mathrm{g} /$ liter) of the Lieber-Decarli liquid diet used in the experiments ${ }^{1}$

\begin{tabular}{lrr}
\hline & Control & Ethanol \\
\hline Protein & & \\
Casein & 41.4 & 41.4 \\
L-Cystine & 0.5 & 0.5 \\
DL-Methionine & 0.3 & 0.3 \\
Carbohydrate: & & \\
Maltose-Dextrins & 114.04 & 24.4 \\
Fats & & \\
Corn Oil & 8.50 & 8.50 \\
Olive Oil & 28.40 & 28.40 \\
Ethyl Linoleate & 2.70 & 2.70 \\
Ethanol & 0.00 & 50.40 \\
Vitamin Mix-711 & 5.00 & 5.00 \\
Salt Mix-711 & 13.43 & 13.43 \\
\hline
\end{tabular}

${ }^{1}$ Diets were purchased from Bioserv, Inc. (Frenchtown, NJ). Both groups of rats consumed an average of $70 \mathrm{ml} / \mathrm{day} / \mathrm{rat} 1 \mathrm{ml}$ contains 1 kcal.

Table 2. Initial and final maternal body weight in the groups of rats studied ${ }^{1}$

\begin{tabular}{lllll}
\hline & & \multicolumn{3}{c}{ Alcohol +10} \\
& Control & Alcohol & mg zinc & mg zinc \\
\hline Initial & $180 \pm 5$ & $178 \pm 4$ & $183 \pm 6$ & $174 \pm 6$ \\
Final & $293 \pm 11$ & $297 \pm 14$ & $292 \pm 10$ & $294 \pm 14$ \\
\hline
\end{tabular}

${ }^{1}$ Values are mean \pm S.E.

Table 3. Body weight of the fetuses and placentas of the control, alcohol, alcohol $+10 \mathrm{mg}$ zinc and alcohol $+40 \mathrm{mg}$ zinc group ${ }^{1}$

\begin{tabular}{lccc}
\hline & & \multicolumn{2}{c}{ Body Weight $(\mathrm{g})$} \\
\cline { 3 - 4 } & No & Fetuses & Placenta \\
\hline Control & 78 & $2.8 \pm 0.02^{2}$ & $0.4 \pm 0.02^{2}$ \\
Alcohol & 72 & $2.2 \pm 0.01$ & $0.52 \pm 0.02$ \\
Alcohol + 10 mg zinc & 64 & $2.2 \pm 0.02$ & $0.58 \pm 0.02$ \\
Alcohol + 40 mg zinc & 70 & $2.2 \pm 0.03$ & $0.56 \pm 0.02$ \\
\hline
\end{tabular}

${ }^{1}$ Values are mean \pm S.E.

${ }^{2}$ Mean values in the control group are significantly different from corresponding mean values in all three groups studied $(P<0.01)$. studied. Mean gain in maternal body weight was $100 \pm 10 \mathrm{~g}$. Table 3 depicts body weight of the fetuses and placentas in the offspring of the rats studied. Mean body weight in the fetuses of the pair-fed control group was significantly greater than corresponding mean values in the alcohol group and in the two alcohol groups supplemented with 10 or $40 \mathrm{mg}$ of zinc/liter $(P<0.01)$. Mean placental weight in the pair-fed control group and in the alcohol group was similar to our previously reported values (5).

Table 4 depicts mean values for placental and fetal uptake of $\left[{ }^{65} \mathrm{Zn}\right]$ in the groups studied. Uptake was expressed as \% of injected dose per $g$ of placental or fetal tissue. Mean placental and fetal uptake were significantly greater in the pair-fed controls compared with corresponding mean values in the alcohol group and in the alcohol group supplemented with zinc $(P<0.01)$. There were no significant differences between corresponding mean values of placental and fetal uptake in the alcohol and zinc supplemental groups.

Table 5 depicts zinc concentration in maternal and fetal tissues of the rats studied. Serum zinc concentration was significantly decreased in the alcohol group compared to the other three groups; however, there were no significant differences between liver and femur levels in all groups studied. Mean placental and fetal zinc concentration in the pair-fed controls was significantly greater than corresponding mean values in alcohol and alcohol with zinc supplemented groups $(P<0.01)$. Mean ethanol level in the maternal blood was $100 \pm 5 \mathrm{mg} / \mathrm{dl}$. There were no significant differences in maternal ethanol level between the experimental groups.

\section{DISCUSSION}

Several experimental observations have indicated that ethanol inhibits intestinal $(21)$ and placental transport $(6,10)$ of nutrients. The intestinal transport of glucose, amino acids, water and electrolytes, vitamins, and several minerals and trace elements were shown to be inhibited by ethanol (21). Furthermore, ethanol has been shown to inhibit in vivo the placental transport of certain amino acids such as $\mathrm{L}$-valine and $\alpha$-aminoisobutyric acid $(6,16)$. Similarly, the effect of ethanol on placental uptake of amino acids has been shown by two in vitro studies $(4,10)$.

Recently, we reported that maternal ethanol ingestion caused a specific defect in placental transport of zinc; moreover, total fetal zinc concentration in the offspring of mothers fed ethanol during pregnancy was significantly decreased compared to corresponding mean values in pair-fed controls (5). Because zinc is a known

Table 4. $\left[{ }^{65} \mathrm{Zn}\right]$ uptake as \% of injected dose/g of fetal and placental tissues in the rats studied ${ }^{1}$

\begin{tabular}{|c|c|c|c|c|}
\hline & Control $n=78$ & $\begin{array}{l}\text { Alcohol } \\
n=72\end{array}$ & $\begin{array}{c}\text { Alcohol }+10 \mathrm{mg} \text { zinc/liter } \\
n=64\end{array}$ & $\begin{array}{c}\text { Alcohol }+40 \mathrm{mg} \text { zinc/liter } \\
n=70\end{array}$ \\
\hline $\begin{array}{l}\text { Placental uptake }\left[{ }^{65} \mathrm{Zn}\right] / \mathrm{g} \\
\text { tissue }\end{array}$ & $1.37 \pm 0.02^{2}$ & $0.86 \pm 0.02$ & $0.88 \pm 0.02$ & $0.91 \pm 0.03$ \\
\hline $\begin{array}{l}\text { Fetal uptake }\left[{ }^{65} \mathrm{Zn}\right] / \mathrm{g} \text { tis- } \\
\text { sue }\end{array}$ & $0.09 \pm 0.01^{2}$ & $0.05 \pm 0.002$ & $0.056 \pm 0.001$ & $0.06 \pm 0.003$ \\
\hline
\end{tabular}

${ }^{1}$ Values are mean \pm S.E.

${ }^{2}$ Mean values in the control group are significantly different from corresponding mean values in alcohol and alcohol + zinc supplemented groups $(P<0.01)$. Mean vlaues in the alcohol group are not statistically significant from corresponding mean values in the supplemented groups.

Table 5. Zinc concentration in maternal and fetal tissues of the rats studied ${ }^{1}$

\begin{tabular}{|c|c|c|c|c|}
\hline & Control & Alcohol & $\begin{array}{l}\text { Alcohol }+10 \mathrm{mg} \\
\text { zinc/liter }\end{array}$ & $\begin{array}{c}\text { Alcohol }+40 \mathrm{mg} \\
\text { zinc/liter }\end{array}$ \\
\hline Serum $(\mu \mathrm{g} / \mathrm{dl})$ & $132 \pm 10^{2}$ & $90 \pm 5$ & $134 \pm 7$ & $135 \pm 9$ \\
\hline Liver & $98 \pm 5$ & $92 \pm 4$ & $97 \pm 6$ & $96 \pm 6$ \\
\hline Femur & $260 \pm 5$ & $251 \pm 7$ & $253 \pm 7$ & $243 \pm 6$ \\
\hline Placenta & $1.32 \pm 0.04^{3}$ & $1.16 \pm 0.02$ & $1.12 \pm 0.02$ & $1.12 \pm 0.02$ \\
\hline Total fetal body concentration & $2.4 \pm 0.02^{3}$ & $1.9 \pm 0.02$ & $1.9 \pm 0.03$ & $2.0 \pm 0.03$ \\
\hline
\end{tabular}

${ }^{1}$ Values are mean \pm S.E. and expressed as $\mu \mathrm{g} / \mathrm{g}$ dry weight.

${ }^{2}$ Mean value in the control group is significantly different from corresponding mean values in the alcohhol group $(P<0.01)$.

${ }^{3}$ Mean values in control group are significantly different from corresponding mean values in alcohol and alcohol + zinc supplementation $(P<0.01)$. 
constituent of a number of important metallo-enzymes, including thymidine kinase, DNA and RNA polymerase (2), prenatal zinc deficiency in the rat and man has been associated with both growth retardation and congenital malformation $(7,11,18)$.

Based on these observations, we postulated that part of the features of fetal alcohol syndrome such as growth retardation may be due to decreased zinc supply to the fetus. Whether the defect in placental transport of zinc is permanent or can be overcome by supplemental zinc is not known. Furthermore, one can ask from a clinical point of view if fetal alcohol syndrome can be prevented by zinc supplementation? Our study design allowed us to examine specifically the role of supplemental zinc alone while all four groups of animals were isocalorically pair-fed. The results of our study agreed with our previous studies (5) and that of others $(1,6$, $8,9,10,19,20)$, in that ethanol ingestion during pregnancy results in growth retarded fetuses compared to isocalorically pair-fed controls; moreover, placental weight in mothers fed ethanol was significantly greater than pair-fed controls. These results are also in agreement with other studies $(5,20)$. Similar to our previously published data, chronic ethanol ingestion during pregnancy results in significant decrease in placental and fetal uptake of $\left[{ }^{65} \mathrm{Zn}\right]$ compared to isocalorically fed controls. Supplementation of the ethanol diet with $10 \mathrm{mg}$ of zinc (twice the amount of zinc in the ethanol diet) or $40 \mathrm{mg}$ of zinc (eight times the amount of zinc in the ethanol diet) did not affect fetal body weight, placental weight, placental and fetal uptake of [ ${ }^{65} \mathrm{Zn}$ ], and total fetal zinc concentration. Our results indicate the defect in placental zinc transport cannot be overcome by either physiologic or pharmacologic doses of zinc. These findings are in agreement with recent observations of Fisher et al. (4), which indicated irreversible inhibition of placental uptake of a $\alpha$-aminoisobutyric acid by ethanol.

\section{REFERENCES AND NOTES}

1. Chernoff, C. F.: The fetal alcohol syndrome in mice: An animal model. Teratology, 15: 223 (1977).

2. Duncan, J. R. and Hurley, L. S.: Thymidine kinase and DNA polymerase activity in normal and zinc deficient developing rat embryo. Proc. Soc. Exp. Biol. Med., 159: 39 (1978)

3. Eckhert, C. D. and Hurley, L. S.: Reduced DNA synthesis in zinc deficiency. J. Nutr., 107: 855 (1977).
4. Fisher, S., Atkinson, M., Holzman, I, David, R., and Vantheil, D.: Selective fetal malnutrition: A new concept in the fetal alcohol syndrome. Pediatr. Res. (Abstract), 549: 15 (1981)

5. Ghishan, F. K., Patwardhan, R., and Greene, H. L.: Fetal alcohol syndrome Inhibition of placental transport of zinc as a potential mechanism for fetal growth retardation. J. Lab. Clin. Med., 100: 45 (1982).

6. Grace, W. and Lin, J.: Effect of ethanol feeding during pregnancy on placental transfer of $\alpha$ aminoisobutyric acid in the rat. Life Sci., 28: 595 (1981).

7. Hambridge, K. M., Neldner, K. H., and Walravens, P. A.: Zinc, acrodermatitis enteropathica and congenital malformations. Lancet, 1: 577 (1975).

8. Hanson, J. W., Jones, K. L., and Smith, D. W.: Fetal alcohol syndrome: Experience with 41 patients. J. Am. Med. Assoc., 235: 1458 (1976).

9. Henderson, G. I., Hoyumpa, A. M., McClain, C., and Schenker, S.: Effect of chronic and acute alcohol administration on fetal development in the rat: alcoholism. Clin. Exp. Res., 3: 99 (1979).

10. Henderson, G. I., Turner, D., Patwardhan, R., Lumen, L., Hoyumpa, A., and Schenker, S.: Inhibition of placental valine uptake after acute and chronic maternal ethanol consumption. J. Pharmacol. Exp. Ther., 216: 465 (1981).

11. Hurley, L. S. and Mutch, P. B.: Prenatal and postnatal development after transitory gestational zinc deficiency in rats. J. Nutr., 103: 649 (1973).

12. Huntsberger, D. V. and Leaverton, P. E.: Statistical inference in the biomedical sciences. Allyn and Bacon, Inc. Boston, MA (1970).

13. Jones, K. L. and Smith, D. W.: Recognition of the fetal alcohol syndrome in early infancy. Lancet, 2: 999 (1973).

14. Jones, K. L., Smith, D. W., Ulleland, C. N., and Streissguth, A. P.: Pattern of malformation in offspring of chronic alcoholic mother. Lancet, 1: 1267 (1973).

15. LeDain, G.: Commission of Inquiry into Non-Medical Use of Drugs. Final Report, Ottawa (1973) Information-Canada.

16. Patwardhan, R., Schenker, S., Henderson, G., Abumrad, N., and Hoyumpa, A. Short term and long term ethanol administration inhibits the placental uptake and transport of valine in rats. J. Lab. Clin. Med., 98: 251 (1981).

17. Quellette, E. M., Rosett, H. L., and Roseman, P.: Adverse effects on offspring of maternal alcohol abuse during pregnancy. N. Engl. J. Med., 297: 528 (1977).

18. Sever, L. E. Zinc deficiency in man. Lancet, $1: 887$ (1973).

19. Tze, W. J. and Lee, M.: Adverse effects of maternal alcohol consumption on pregnancy and fetal growth in rats. Nature, 257: 479 (1975).

20. Wiener, S., Shoemaker, W. J., Koda, L. Y., and Bloom, F.: Interaction of ethanol and nutrition during gestation: Influence on maternal and offspring development in the rat. J. Pharmacol. Exp. Ther., 216: 572 (1981).

21. Wilson, F. A. and Hoyumpa, A. M.: Ethanol and small intestinal transport. Gastroenterology, 76: 388 (1979).

22. Requests for reprints should be addressed to: Dr. Fayez K. Ghishan, Associate Professor of Pediatrics, Department of Pediatrics, Vanderbilt University Medical Center, Nashville, TN 37232.

23. This study was supported by grants from the National Institute of Arthritis, Metabolism and Digestive Disease, No. AM 26657-02 and the Bristol-Myers Company, New York, NY.

24. Received for publication August 18, 1982

25. Accepted for publication December 7, 1982.

Printed in U.S.A 